\title{
MANAJEMEN RISIKO PADA P2B UINSA \\ MENGGUNAKAN FRAMEWORK ISO 31000
}

\author{
Arif Rahman Fauzi, Sururin Darina, Ahmad Rizki Habibi, Rais Bagus Prakoso, \\ Muqoffi Khosyatullah, Mochamad Haidar Wassi Yusron, Indri Sudanawati Rozaz ${ }^{\bowtie}$ \\ UIN Sunan Ampel, Surabaya, Indonesia \\ Email: indrisrozaz@uinsby.ac.id
}

DOI: https://doi.org/10.46880/methoda.Vol11No3.pp194-200

\begin{abstract}
P2B (P2B) UIN Sunan Ampel Surabaya (UINSA) is a university support institution tasked with developing student competencies in the field of language to produce competent graduates, especially in language. Language skill activities, Arabic, English, and language skills are mandatory for all students and foreign students who have TOAFL and TOEFL certificates. The position, duties, and functions of P2B UINSA Surabaya have three main tasks, namely conducting intensive Arabic and English language training to educate students in studying foreign language literature books, then helping to improve students' foreign language skills to prepare students to continue their education directly abroad. country, and assisting students in mastering foreign languages to be useful in social life. In carrying out their duties, the P2B UINSA Surabaya faces risks. One of the problems that are often faced is the issue of certificate printing which poses a risk. Therefore, to analyze this problem, ISO 31000 is used. This is done so that P2B parties can manage risks that can become obstacles to organizational goals. Data collection was carried out using a direct interview method to the person in charge of the language center to ask the level of possible risks that occurred. In this study using the P2B UINSA Surabaya research object and found 7 risks including 2 high risk, 4 moderate risk and 1 low risk originating from 3 aspects. which is then carried out to identify the scale and priority of the risk. The results of this study are treatment recommendations for the risks that exist in P2B UINSA.
\end{abstract}

Keyword: P2B, TOAFL, TOEFL, Language.

\begin{abstract}
ABSTRAK
P2B (P2B) UIN Sunan Ampel Surabaya (UINSA) adalah lembaga pendukung universitas yang bertugas dalam pengembangan kompetensi mahasiswa dalam bidang bahasa untuk menghasilkan lulusan yang berkompeten terutama dalam berbahasa. Kegiatan keterampilan berbahasa, bahasa Arab, bahasa Inggris, dan bahasa diwajibkan bagi seluruh mahasiswa dan mahasiswa asing yang memiliki sertifikat TOAFL dan TOEFL. Kedudukan, tugas dan fungsi P2B UINSA Surabaya ada tiga tugas pokok, yaitu mengadakan pelatihan intensif bahasa arab dan inggris guna mengedukasi para mahasiswa dalam mempelajari buku literatur berbahasa asing, kemudian membantu meningkatkan mahasiswa dalam kemampuan berbahasa asing untuk menyiapkan mahasiswa dalam melanjutkan pendidikan tingkat langsung ke luar negeri, dan membantu mahasiswa dalam penguasaan bahasa asing agar berguna pada kehidupan bermasyarakat. Dalam menjalankan tugasnya, pihak P2B UINSA Surabaya berhadapan dengan resiko. Salah satu masalah yang sering dihadapi adalah masalah percetakan sertifikat yang mwnimbulkan risiko. Maka dari itu untuk menganalisa masalah tersebut maka digunakan ISO 31000. Hal ini dilakukan agar pihak P2B dapat mengelola resiko yang dapat menjadi penghambat tujuan organisasi.
\end{abstract}

194 | MAJALAH ILMIAH METHODA Volume 11, Nomor 3, September-Desember 2021: 194-200 ISSN: 2088-9534 (media cetak) - ISSN: 2656-6931 (media online) 
Pengambilan data dilakukan menggunakan metode wawancara langsung terhadap penanggung jawab pusat bahasa untuk menanyakan tingkat kemungkinan risiko yang terjadi. Pada penelitian ini menggunakan objek penelitian P2B UINSA Surabaya dan ditemukan 7 risiko diantaranya 2 risiko high, 4 resiko moderate dan 1 resiko low yang berasal dari 3 aspek yang kemudian dilakukan identifikasi skala dan prioritas resikonya. Hasil dari penelitian ini yaitu rekomendasi treatment untuk risiko yang ada pada P2B UINSA.

Kata Kunci: $P 2 B$, TOAFL, TOEFL, Bahasa.

\section{PENDAHULUAN}

P2B (P2B) UINSA Surabaya adalahlembaga yang berguna sebagai unsur pendukung universitas. P2B (P2B) melaksanakan berbagai kegiatan peningkatan kompetensi berbahasa asing dalam rangka mengembangkan skill dan mutu civitas akademik beserta lulusan yang menjunjung tinggi profesionalitas di dunia kerja. P2B (P2B) UINSA Surabaya melaksanakan kegiatan keterampilan berbahasa asing. Kemampuan bahasa Arab dan bahasa Inggris juga diwajibkan bagi seluruh mahasiswa dan civitas akademik. Kegiatan pelatihan bahasa Arab dan Inggris yang diadakan oleh $\mathrm{P} 2 \mathrm{~B}$ UINSA juga memiliki sertifikat TOAFL dan TOEFL.

Kedudukan, tugas dan fungsi P2B UINSA memiliki tiga fungsi serta tugas. yaitu mengadakan pelatihan intensif bahasa arab dan inggris guna mengedukasi para mahasiswa dalam mempelajari buku literatur berbahasa asing. yang kedua, membantu peningkatan penguasaan bahasa asing sehingga dapat sehingga dapat membantu mahasiswa yang akan melanjutkan pendidikan ke luar negeri dan yang ketiga, dapat membantu penguasaan bahasa asing agar dapat dibawa oleh mahasiswa dalam kehidupan bermasyarakat dan bekerja.

Dalam menjalankan tugasnya, maka pihak P2B UINSA akan berhadapan dengan suatu resiko, baik risiko mengenai aset maupun risiko proses bisnis yang mempengaruhi proses kelancaran pekerjaan P2B UINSA dan menghambat pekerjaan P2B UINSA. Resiko yang paling sering dihadapi adalah tidak adanya anggaran dari universitas untuk mencetak sertifikat di luar uinsa dan fasilitas serta sdm percetakan uinsa yang tidak memadai.

Pihak P2B UINSA memiliki kebutuhan untuk mengelola risiko guna mengurangi kerugian yang timbul akibat risiko. Dengan ini maka digunakan ISO 31000 untuk mengelola risiko dengan tahapan dan tujuan yang jelas agar pihak P2B dapat mengelola resiko yang dapat menjadi penghambat tujuan organisasi.

\section{TINJAUAN PUSTAKA \\ Proses Manajemen Risiko}

Proses manajemen risiko atau risk management process adalah bagian yang umum dalam suatu manajemen organisasi atau organisasi (Susilo, 2018). Manajemen risiko harus menjadi suatu bagian penting bagi organisasi, praktek berorganisasi dan proses bisnis dalam organisasi (Labombang, 2011). Proses dalam melakukan risk management meliputi 5 (lima) kegiatan yaitu komunikasi dan konsultasi risiko, menentukan konteks risiko, pengukuran risiko, perlakuan risiko serta monitoring dan review risiko (Monica \& Prabowo, 2020; Sepang, Tjakra, Langi, \& Walangitan, 2013). Hal tersebut dapat dilihat pada gambar proses manajemen risiko di bawah ini:

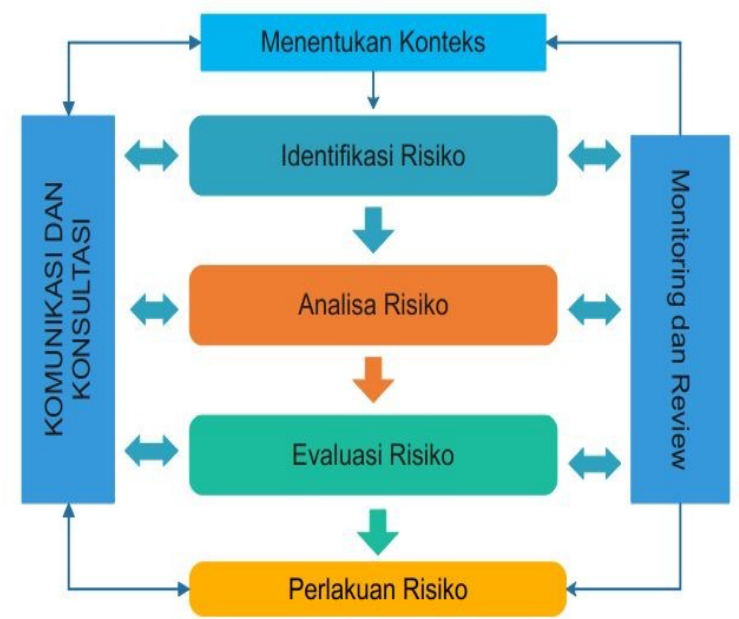

Sumber: (Meilania, 2014)

Gambar 1. Proses Pengelolaan Risiko ISO 31000 


\section{Menentukan Konteks}

Langkah awal proses pengelolaan risiko adalah menentukan tujuan yang ingin dicapai organisasi atau organisasi. Pada menentukan konteks ini, P2B UINSA bertujuan untuk mengembangkan kompetensimahasiswa dalam berbahasa asing, yaitu bahasa Inggris dan bahasa Arab yang nantinya berguna bagi mahasiswa sendiri danberguna untuk masyarakat.

Kegiatan pelatihan bahasa Arab dan Inggris yang diadakan oleh P2B UINSA jugamemiliki sertifikat TOAFL dan TOEFL.

\section{Identifikasi Risiko}

Hal yang dilakukan pada tahap ini adalah mengidentifikasi kemungkinan risiko yang akan terjadi pada sebuah organisasi atau organisasi. Proses pengidentifikasian risiko pada P2B UINSA yang diambil adalah proses bisnis, dimana terdapat tujuh kemungkinan risiko yang dapat mengganggu tujuan awal dari P2B UINSA.

\section{Analisa Risiko dan Evaluasi Risiko}

Analisa risiko bertujuan untuk mengidentifikasi kemungkinan dan dampak risiko. Menurut Water pada penerapan ISO 31000 Dalam Pengelolaan Risiko Pada Bank Perkreditan Rakyat (Meilania, 2014) menentukan kemungkinan terjadinya suatu peristiwa, dapat dilakukan dengan pendekatan, yaitu:

1. Dengan menggunakan pengetahuan mengenai situasi untuk menghitung probabilitas.

2. Dengan menggunakan data historis untuk melihat seberapa sering peristiwa tersebut terjadi di masa lalu dan digunakan untuk menentukan perkiraan peristiwa tersebut akan terjadi di masa yang akan datang.

3. Bertanya pada risk owner atau ahli atau karyawan untuk memperoleh pandangan kemungkinan suatuperistiwa terjadi.

4. Perlakuan Risiko, dimana setiap risiko memerlukan perlakuan yang khas untuk tiap risiko itu sendiri. Untuk setiap risiko yang memerlukan risiko, perlu dilakukan pemeriksaan ulang yang cukup komprehensif terhadap informasi dan data hasil analisis risiko. Hal ini diperlukan untuk memahami sumber atau penyebab risiko, apa pemicu timbulnya risiko, bagaimana besar kemungkinannyaterjadi, serta seberapa besar dampaknya.

\section{Matriks Manajemen Risiko}

Estimasi pada manajemen risiko dapat berupa kuantitatif, semi kuantitatif maupun kualitatif dalam hal kemungkinan (likelihood) serta terjadinya dampak (impact). Untuk Memilih metode yang tepat dalam menangani kerugian yang diakibatkan oleh risiko, dapat dibuat semacam matriks yang dapat mengklasifikasikan berbagai ancaman yang akan menjadikan kerugian.

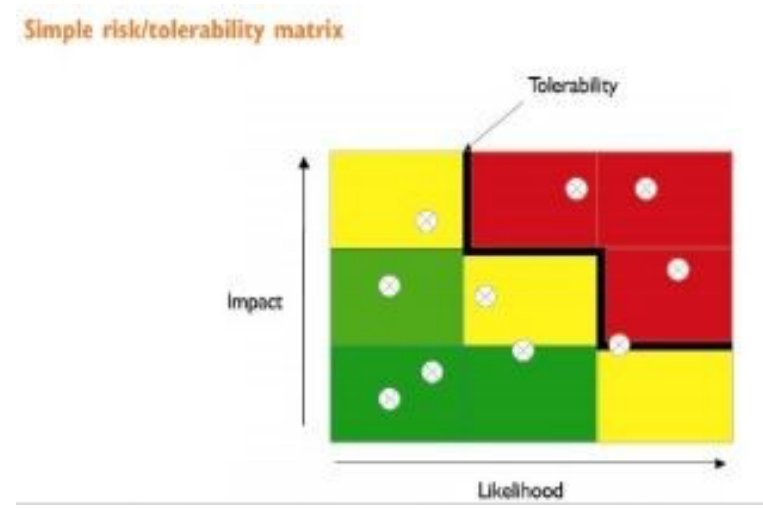

Gambar 2. Matriks Risiko

Pada Gambar 2 penilaian ini perludilakukan dengan mengevaluasi kemungkinan risiko yang ada. terdapat tiga kategorisasi yakni tinggi, menengah dan rendah yang masing-masing mungkin cukup untuk menghasilkan matriks risiko "3x3" seperti yang ada pada Gambar 2. Jika evaluasi yang dibutuhkan lebih khusus maka dapat menggunakan matriks " $5 \times 5$ ".

\section{METODE PENELITIAN}

Berdasarkan masalah-masalah yang telah dipaparkan pada pendahuluan di atas maka untuk menganalisa masalah tersebut digunakan ISO 31000 sebagai framework dan mitigasi.

Pada penelitian ini metode yang digunakan adalah metode penelitian kualitatif, yakni penelitian yang bersumber dari wawancara langsung terhadap penanggung jawab pusat 
bahasa untuk menanyakan tingkat kemungkinan risiko yang terjadi.

Kemudian untuk penilaian resiko penulis menggunakan matriks $3 \times 3$ karena dirasa cocok berdasarkan studi kasus ini.

\section{HASIL DAN PEMBAHASAN}

Pada tahapan ini dibahas evaluasi risiko, beberapa kemungkinan resiko yang telah melalui proses identifikasi dan analisis. hasil dari evaluasi akan dimasukan ke dalam sebuah matriks risiko yang dibuat berdasarkan likelihood serta impact, kemudian pembentukan matriks evaluasi risiko didapatkan dari parameter yang sudah ditentukan melalui evaluasi risiko (Budiono, Sarwiyata, \& Alamsyah, 2014).

Dilihat secara detail, parameter yang digunakan dalam evaluasi risiko dapat dilihat dalam Tabel 1 dan Tabel 2 sementara yang dijadikan matrik evaluasi risiko berdasarkan probabilitas (likelihood) dan dampak (impact).

Tabel 1. Keterangan Likelihood

\begin{tabular}{|l|l|l|}
\hline Nilai & Kriteria & Keterangan \\
\hline 1 & Low & $\begin{array}{l}\text { Risiko tersebut hampir } \\
\text { tidak pernah terjadi }\end{array}$ \\
\hline 2 & Moderate & $\begin{array}{l}\text { Risiko tersebut kadang } \\
\text { terjadi }\end{array}$ \\
\hline 3 & High & $\begin{array}{l}\text { Risiko tersebut pasti } \\
\text { terjadi }\end{array}$ \\
\hline
\end{tabular}

Pada Tabel 1 likelihood merupakan potensi keseringan dari sumber ancaman.

Tabel 2. Keterangan Impact

\begin{tabular}{|l|l|l|}
\hline Nilai & Kriteria & Keterangan \\
\hline 1 & Low & $\begin{array}{l}\text { Tidak mengganggu } \\
\text { aktivitas organisasi }\end{array}$ \\
\hline 2 & Moderate & $\begin{array}{l}\text { Menyebabkan gangguan pada } \\
\text { proses bisnis sehingga } \\
\text { jalannya aktivitas organisasi } \\
\text { terhambat }\end{array}$ \\
\hline 3 & High & $\begin{array}{l}\text { Aktivitas organisasi terhenti } \\
\text { karena proses bisnis } \\
\text { mengalami gangguan } \\
\text { total }\end{array}$ \\
\hline
\end{tabular}

Pada Tabel 2 impact merupakan suatu dampak nyata yang dapat diukur. Pada saat analisis risiko, ditemukan bahwa terdapat 10 kemungkinan risiko. Setelah melakukan survey dan wawancara terhadap pihak P2B UINSA, setelah dikonfirmasi hasilnya terdapat 7 kemungkinan risiko yang dapat dilihat seperti pada Tabel 3 dibawah ini. Setelah mendapat konfirmasi dari pihak P2B UINSA, kemudian membuat tabel identifikasi kemungkinan risiko yang digambarkan seperti pada Tabel 3 .

Tabel 3. Tabel Kemungkinan Risiko

\begin{tabular}{|c|c|c|c|}
\hline No & Proses Bisnis & Kode & $\begin{array}{l}\text { Kemungkinan } \\
\text { Risiko }\end{array}$ \\
\hline 1 & $\begin{array}{l}\text { P2B } \\
\text { mengadakan } \\
\text { recruitment dosen } \\
\text { intensif }\end{array}$ & R01 & $\begin{array}{l}\text { Proses perekrutan } \\
\text { dosen lebih } \\
\text { lama }\end{array}$ \\
\hline 2 & $\begin{array}{l}\text { P2B } \\
\text { bekerjasama } \\
\text { dengan fakultas } \\
\text { untuk melakukan } \\
\text { retest bagi } \\
\text { mahasiswa yang } \\
\text { belum memenuhi } \\
\text { nilai }\end{array}$ & R02 & $\begin{array}{l}\text { Keterlambatan } \\
\text { pihak fakultas } \\
\text { untuk } \\
\text { mengadakan } \\
\text { pretest bagi } \\
\text { mahasiswa }\end{array}$ \\
\hline 3 & $\begin{array}{l}\text { P2B menerima } \\
\text { nilai dari } \\
\text { koordinator } \\
\text { setiap fakultas }\end{array}$ & R03 & $\begin{array}{l}\text { Kesalahan data } \\
\text { yang diberikan } \\
\text { oleh fakultas }\end{array}$ \\
\hline 4 & \multirow{2}{*}{$\begin{array}{l}\text { P2B mencetak } \\
\text { sertifikat } \\
\text { mahasiswa yang } \\
\text { telah memenuhi } \\
\text { nilai }\end{array}$} & R04 & $\begin{array}{l}\text { Tidak adanya } \\
\text { anggaran dari } \\
\text { universitas untuk } \\
\text { mencetak } \\
\text { sertifikat di } \\
\text { luar uinsa }\end{array}$ \\
\hline 5 & & R05 & $\begin{array}{l}\text { fasilitas dan sdm } \\
\text { percetakan uinsa } \\
\text { yang tidak } \\
\text { memadai }\end{array}$ \\
\hline 6 & \multirow{2}{*}{$\begin{array}{l}\text { P2B } \\
\text { mengadakan kelas } \\
\text { pengembangan/ } \\
\text { remidi bagi } \\
\text { mahasiswa yang } \\
\text { belum memenuhi } \\
\text { nilai }\end{array}$} & R06 & $\begin{array}{l}\text { Kurangnya ruang } \\
\text { kelas }\end{array}$ \\
\hline 7 & & R07 & $\begin{array}{l}\text { Terlalu banyak } \\
\text { mahasiswa yang } \\
\text { akan mengikuti } \\
\text { kelas KP }\end{array}$ \\
\hline
\end{tabular}

Dari kemungkinan risiko yang ada seperti pada Tabel 3 maka dapat dianalisis dampak yang dikelompokkan seperti pada Tabel 4 dibawah ini. 
Tabel 4. Tabel Dampak Risiko

\begin{tabular}{|c|c|c|}
\hline Kode & $\begin{array}{l}\text { Kemungkinan } \\
\text { Risiko }\end{array}$ & $\begin{array}{l}\text { Dampak } \\
\text { Risiko }\end{array}$ \\
\hline R01 & $\begin{array}{l}\text { Proses } \\
\text { perekrutan } \\
\text { dosen menjadi } \\
\text { lebihlama }\end{array}$ & $\begin{array}{l}\text { Kegiatanbelajar } \\
\text { mengajar } \\
\text { terganggu }\end{array}$ \\
\hline R02 & $\begin{array}{l}\text { Keterlambatan } \\
\text { pihakfakultas } \\
\text { untuk } \\
\text { mengadakan } \\
\text { pretest } \\
\text { bagi mahasiswa }\end{array}$ & $\begin{array}{l}\text { Kendala mahasiswa } \\
\text { dalam } \\
\text { melanjutkan proses } \\
\text { skripsi }\end{array}$ \\
\hline R03 & $\begin{array}{l}\text { Kesalahan data } \\
\text { yang diberikan } \\
\text { oleh fakultas }\end{array}$ & $\begin{array}{l}\text { 1. Kesalahan cetak } \\
\text { sertifikat } \\
\text { 2. Komplain } \\
\text { mahasiswa } \\
\text { 3. Kerugian anggaran } \\
\text { untuk mencetak } \\
\text { sertifikat baru } \\
\text { 4. Data mahasiswa yang } \\
\text { diterima P2B tidak } \\
\text { valid }\end{array}$ \\
\hline R04 & $\begin{array}{l}\text { Tidak adanya } \\
\text { anggaran dari } \\
\text { universitas untuk } \\
\text { mencetak } \\
\text { sertifikat di luar } \\
\text { UINSA }\end{array}$ & $\begin{array}{l}\text { Mengeluark an } \\
\text { anggaran pribadi } \\
\text { P2B untuk mencetak } \\
\text { di luar UINSA }\end{array}$ \\
\hline R05 & $\begin{array}{l}\text { Fasilitas dan } \\
\text { SDM percetakan } \\
\text { UINSA yang } \\
\text { tidak memadai }\end{array}$ & $\begin{array}{l}\text { 1. Keterlambat an } \\
\text { pencetakan } \\
\text { sertifikat } \\
\text { 2. Mengeluark an } \\
\text { anggaran pribadi } \\
\text { P2B untuk } \\
\text { mencetak di luar } \\
\text { UINSA }\end{array}$ \\
\hline R06 & $\begin{array}{l}\text { Kurangnya ruang } \\
\text { kelas }\end{array}$ & $\begin{array}{l}\text { Antrian kelas remidi } \\
\text { semakin } \\
\text { panjang }\end{array}$ \\
\hline R07 & $\begin{array}{l}\text { Terlalu banyak } \\
\text { mahasiswa yang } \\
\text { akan mengikuti } \\
\text { kelas KP }\end{array}$ & $\begin{array}{l}\text { Ruang kelas yang } \\
\text { digunakan tidak } \\
\text { mencukupi untuk } \\
\text { menampung Mahasiswa } \\
\text { pendaftar } \\
\text { remidi }\end{array}$ \\
\hline
\end{tabular}

Pada Tabel 5 dijelaskan penilaian risiko berdasarkan kode risiko dan penilaian menggunakan skala likelihood dan impact yang tertera pada Tabel 1 dan Tabel 2. Sehinggga menghasilkan nilai pengelompokkan risiko seperti yang terdapat pada Tabel 5 sebagai peninjau penilaian risiko/risk assessment.
Nilai risiko pada kolom 4 Tabel 5 diambil berdasarkan pemetaan likelihood dan impact pada matriks yang terdapat pada Tabel 6 . Sehingga didapatkan hasil R01 kategori Low, R2 kategori Moderate, dan seterusnya. Karena nilai low, moderate, dan high didasarkan pada warna hijau, kuning,dan merah pada Tabel 6.

Tabel 5. Tabel Pengelompokkan Risiko

\begin{tabular}{|c|c|c|c|c|}
\hline Kode & $\begin{array}{l}\text { Kemungkinan } \\
\text { Risiko }\end{array}$ & $\begin{array}{l}\text { Nilai } \\
\text { Likeli } \\
\text { hood }\end{array}$ & $\begin{array}{l}\text { Nlai } \\
\text { Impact }\end{array}$ & $\begin{array}{l}\text { Nilai } \\
\text { Risiko }\end{array}$ \\
\hline R01 & $\begin{array}{l}\text { Membutuhkan } \\
\text { waktu yang } \\
\text { lama untuk } \\
\text { perekrutan } \\
\text { dosen }\end{array}$ & 2 & 1 & Low \\
\hline R02 & $\begin{array}{l}\text { Keterlambatan } \\
\text { pihak fakultas } \\
\text { untuk } \\
\text { mengadakan } \\
\text { retest bagi } \\
\text { mahasiswa }\end{array}$ & 1 & 3 & $\begin{array}{l}\text { Moder } \\
\text { ate }\end{array}$ \\
\hline R03 & $\begin{array}{l}\text { Kesalahan data } \\
\text { yang diberikan } \\
\text { oleh fakultas }\end{array}$ & 1 & 3 & $\begin{array}{l}\text { Moder } \\
\text { ate }\end{array}$ \\
\hline R04 & $\begin{array}{l}\text { Tidak adanya } \\
\text { anggaran dari } \\
\text { universitas } \\
\text { untuk mencetak } \\
\text { sertifikat diluar } \\
\text { uinsa }\end{array}$ & 3 & 3 & High \\
\hline \multirow[t]{2}{*}{ R05 } & $\begin{array}{l}\text { fasilitas dan } \\
\text { sdm }\end{array}$ & 3 & 3 & High \\
\hline & $\begin{array}{l}\text { percetakan } \\
\text { uinsa yang } \\
\text { tidak memadai }\end{array}$ & & & \\
\hline R06 & $\begin{array}{l}\text { Kurangnya } \\
\text { ruang kelas }\end{array}$ & 3 & 1 & $\begin{array}{l}\text { Moder } \\
\text { ate }\end{array}$ \\
\hline R07 & $\begin{array}{l}\text { Terlalu banyak } \\
\text { mahasiswa yang } \\
\text { akan mengikuti } \\
\text { kelas KP }\end{array}$ & 3 & 1 & $\begin{array}{l}\text { Moder } \\
\text { ate }\end{array}$ \\
\hline
\end{tabular}

Setelah melalui proses pengelompokkan risiko pada Tabel 5 diatas, maka menghasilkan matriks resiko yang dapatdilihat pada Tabel 6 dibawah ini. 
Tabel 6. Matriks Risiko

\begin{tabular}{|l|l|l|l|l|}
\hline & \multicolumn{4}{|c|}{ Impact } \\
\hline \multirow{4}{*}{$\begin{array}{l}\text { Likelih } \\
\text { ood }\end{array}$} & $\begin{array}{l}\text { High } \\
\text { (3) }\end{array}$ & $\begin{array}{l}\text { Modera } \\
\text { te (2) }\end{array}$ & Low (1) \\
\cline { 2 - 5 } & $\begin{array}{l}\text { Ro4, } \\
\text { R05 } \\
\text { te (2) }\end{array}$ & & $\begin{array}{l}\text { R06, } \\
\text { R07 }\end{array}$ \\
\cline { 2 - 5 } & Low (1) & $\begin{array}{l}\text { R02, } \\
\text { R03 }\end{array}$ & & R01 \\
\hline
\end{tabular}

Berdasarkan Tabel 6 diatas terdapat 2 parameter yaitu impact dan likelihood yang menjelaskan bahwa terdapat 2 high, 3 moderate dan 1 low, sehingga treatment yang diberikan berdasarkan level risiko berbeda. Maka level risiko high memiliki treatmentyang lebih banyak dibandingkan level risiko yang lainnya, hasilnya dapat dilihat pada Tabel 7 dibawah ini.

Tabel 7. Tabel Treatment Risiko

\begin{tabular}{|c|c|c|c|}
\hline Kode & $\begin{array}{l}\text { Kemungkinan } \\
\text { Risiko }\end{array}$ & $\begin{array}{l}\text { Nilai } \\
\text { Risiko }\end{array}$ & Treatment \\
\hline R07 & $\begin{array}{l}\text { Tidak adanya } \\
\text { anggaran dari } \\
\text { universitas untuk } \\
\text { mencetak } \\
\text { sertifikat di luar } \\
\text { uinsa }\end{array}$ & High & $\begin{array}{l}\text {-Mengajukan } \\
\text { proposal } \\
\text { anggaran untuk } \\
\text { sertifikat ke } \\
\text { pihak UINSA } \\
\text {-Mengadakan } \\
\text { kerjasama yang } \\
\text { saling } \\
\text { menguntungk an } \\
\text { dengan berbagai } \\
\text { pihak untuk } \\
\text { mendapatkan } \\
\text { pemasukan } \\
\text {-Melakukan } \\
\text { kegiatan iuran } \\
\text { bulanan untuk } \\
\text { tabungan } \\
\text { percetakan } \\
\text { sertifikat } \\
\text {-Mengajukan } \\
\text { program } \\
\text { pelatihan bahasa } \\
\text { tambahan ke } \\
\text { pihak UINSA, } \\
\text { namun bersifat } \\
\text { berbayar. }\end{array}$ \\
\hline
\end{tabular}

\begin{tabular}{|c|c|c|c|}
\hline R06 & $\begin{array}{l}\text { Fasilitas dan } \\
\text { SDM percetakan } \\
\text { uinsa yang tidak } \\
\text { memadai }\end{array}$ & High & $\begin{array}{l}\text {-Mengajukan } \\
\text { pembaruan } \\
\text { fasilitas } \\
\text {-Mengadakan } \\
\text { training } \\
\text { karyawan } \\
\text { percetakan agar } \\
\text { lebih } \\
\text { berkompeten } \\
\text {-Merekrut SDM } \\
\text { yang } \\
\text { berkompeten }\end{array}$ \\
\hline R05 & $\begin{array}{l}\text { Kesalahan data } \\
\text { yang diberikan } \\
\text { oleh koordinator } \\
\text { fakultas }\end{array}$ & $\begin{array}{l}\text { Moder } \\
\text { ate }\end{array}$ & $\begin{array}{l}\text {-Melakukan } \\
\text { pengecekan } \\
\text { ulang terhadap } \\
\text { data yang } \\
\text { diberikan } \\
\text { koordinator. }\end{array}$ \\
\hline R04 & $\begin{array}{l}\text { Keterlambatan } \\
\text { pihak fakultas } \\
\text { untuk } \\
\text { mengadakan } \\
\text { retest bagi } \\
\text { mahasiswa }\end{array}$ & $\begin{array}{l}\text { Moder } \\
\text { ate }\end{array}$ & $\begin{array}{l}\text {-Mengadakan } \\
\text { koordinasi antara } \\
\text { fakultas dengan } \\
\text { P2B. } \\
\text {-Mendisiplink an } \\
\text { pihak fakultas } \\
\text { untuk lebih } \\
\text { memperhatika n } \\
\text { jadwal retest. }\end{array}$ \\
\hline R03 & $\begin{array}{l}\text { Kurangnya ruang } \\
\text { kelas KP/Remidi }\end{array}$ & $\begin{array}{l}\text { Moder } \\
\text { ate }\end{array}$ & $\begin{array}{l}\text {-Melakukan } \\
\text { pengajuan } \\
\text { penambahan } \\
\text { kelas KP di } \\
\text { fakultas } \\
\text {-Membatasi } \\
\text { jumlah pendaftar } \\
\text { setiap } \\
\text { periodenya. }\end{array}$ \\
\hline R02 & $\begin{array}{l}\text { Terlalu banyak } \\
\text { mahasiswa yang } \\
\text { akan mengikuti } \\
\text { kelas KP/Remidi }\end{array}$ & $\begin{array}{l}\text { Moder } \\
\text { ate }\end{array}$ & $\begin{array}{l}\text {-Menambah } \\
\text { kelas. } \\
\text { - Menambah } \\
\text { gelombang } \\
\text { pendaftaran } \\
\text { remidi. }\end{array}$ \\
\hline R01 & $\begin{array}{l}\text { Lamanya waktu } \\
\text { yang dibutuhkan } \\
\text { untuk perekrutan } \\
\text { dosen. }\end{array}$ & low & $\begin{array}{l}\text { Melakukan } \\
\text { persiapan } \\
\text { perekrutan dosen } \\
\text { yang lebih } \\
\text { terencana. }\end{array}$ \\
\hline
\end{tabular}

\section{KESIMPULAN}

Penelitian analisis manajemen risiko pada P2B UINSA ini menggunakan ISO 31000 yang dimulai dari tahap penilaian risiko. Tahap 
tersebut terdiri dari identifikasi risiko, kemudian analisis risiko dan evaluasi risiko dan tahap perlakuan terhadap risiko atau treatment.

Dari hasil penelitian ini, terdapat 7 kemungkinan risiko yang dapat terjadi pada proses bisnis P2B UINSA. Terdapat 2 kemungkinan risiko yang memiliki level of risk dengan tingkatan tinggi. Lalu terdapat 4 risiko yang memiliki level of risk yang sedang dan biasa atau disebut tingkat moderate. Selain itu ada pula 1 risiko yang memiliki level of risk yang rendah dengan treatment yang tidak terlalu dibutuhkan.

Proses penanggulangan terhadap kemungkinan risiko pada tahap moderate dan rendah sudah dilakukan oleh pihak P2B UINSA, namun proses penanggulangan tersebut dilakukan tanpa dokumentasi yang terkait pada manajemen risiko organisasi. Melalui adanya penelitian ini berharap agar penelitian ini dapat membantu pihak P2B UINSA dalam menyusun dokumentasi yang terkait dengan manajemen risiko organisasi.

\section{DAFTAR PUSTAKA}

Budiono, S., Sarwiyata, T. W., \& Alamsyah, A. (2014). Pelaksanaan Program Manajemen Pasien dengan Risiko Jatuh di Rumah Sakit. Jurnal Kedokteran Brawijaya, 28(1), 78-83.

Labombang, M. (2011). Manajemen risiko dalam proyek konstruksi. SMARTek, 9(1), $39-46$.

Meilania, T. A. A. D. (2014). Penerapan ISO 31000 Dalam Pengelolaan Risiko Pada Bank Perkreditan Rakyat (Studi Kasus Bank Perkreditan Rakyat X). Jurnal Administrasi Bisnis, 10(1), 17-32.

Monica, \& Prabowo, R. (2020). Analisis Manajemen Risiko Sistem Informasi Pengelolaaan Data English Proficiency Test (EPT) dan Portal Informasi di UPT Bahasa Universitas Lampung Menggunakan Metode ISO 31000. Jurnal Komputasi, 8(1), 83-90.

Sepang, B. A. W., Tjakra, J., Langi, J. E. C., \& Walangitan, D. R. O. (2013). Manajemen risiko keselamatan dan kesehatan kerja (K3) pada proyek pembangunan ruko Orlens Fashion Manado. Jurnal Sipil Statik, 1(4), 282-288.
Berbasis ISO 31000: 2018: Panduan untuk Risk Leaders dan Risk Practitioners. Jakarta: Gramedia Widiasarana Indonesia.

Susilo, L. J. (2018). Manajemen Risiko 